\title{
Determining Optimal Moulding Process Parameters by Two Level Factorial Design with Center Points
}

\author{
S.Rajalingam $^{1 *}$ Awang Bono $^{2}$ and Jumat bin Sulaiman ${ }^{3}$ \\ ${ }^{1}$ School of Engineering and Science, Curtin University, CDT 250, 98009, \\ Miri, Sarawak, Malaysia, Email:rajalingam@curtin.edu.my \\ ${ }^{2}$ Universiti Malaysia Sabah, JalanUMS, 88400, Kota Kinabalu, Sabah, \\ Malaysia, Email:²bono@ums.udu.my; ${ }^{3}$ jumat@ums.edu.my
}

\begin{abstract}
Determining optimal process parameter setting critically influences productivity, quality and cost of production in the injection moulding industry. Previously production engineers used trial and error method to determine optimal process parameter setting. Inappropriate machine parameter settings can cause production and quality problems. In this paper the authors used a case study to investigate the moulding machine parameters which will affect the dimensions (length and width) in a plastic component. The machine process setting in use currently caused variations in the dimensions exceeding the specification limit. Therefore the experiment is needed to identify the optimal machine parameter setting which could be set to maintain the dimensions closest to the target value with smallest possible variation. A design of experiments (two level factorial design with center points) was conducted to study the effect of three injection moulding process parameters (mould temperature, injection speed and injection pressure) versus dimensions (length and width). Finally, the optimal process parameters to maintain the dimensions closest to the target values were identified. Statistical results and analysis are used to provide better interpretation of the experiment. The models are form from ANOVA and the models passed the tests for normality and independence assumptions.
\end{abstract}

Keywords: Process, Parameters, Response, Factors, ANOVA, Target Values, Moulding. 


\section{Introduction}

In recent years, the communication products like cell phone are widely applied throughout the world. The designs of cell phone have a tendency to be thin, light and small and more convenient style. Therefore, the shapes of smart cell phone are changing, and more features have to be tightly packed into smaller volumes within the housing. In order to procure more space for the tightly packed components inside, the wall thickness of the housing parts must originally be reduced to less than $3 \mathrm{~mm}$ in thickness [1]. Plastic injection moulding is one of the most important procedures applied for forming an injection-moulded thermoplastic part with a thin-shell feature. Machining parameters, moulding material, product and mould designs are major factors affecting the quality of thermoplastic parts produced by injection moulding. Due to the complexity of injection moulding, numerous mathematical models have been proposed and extensively developed by a growing numbers of studies for the analysis of different stages of the injection moulding process. The process of injection moulding includes filling, packing, cooling, opening the mould cavity, injecting and closing the mould cavity. However, the selection of appropriate machining parameters for the injection moulding operation becomes more difficult as the wall thickness of plastic parts gets thinner [2].

Warpage and shrinkage are among the most significant defects of thin shell thermoplastic part in terms of quality in the process of injection moulding. The level of warpage and shrinkage is highly related to the injection machine parameters setting. Leo and Cuvelliez [3] investigated the influence of the packing parameters and gate geometry on the final dimensions of a moulded part by experiment. Huang and Tai [4] used the computer simulation and the experimental design of the Taguchi method to analyze the effective factors of warpage in an injection moulded part with a thin-shell feature. Ozcelik and Erzumlu [5] explored the determination of efficient minimization of warpage on thin-shell plastic parts by integrating the response surface method and genetic algorithm. Recently, the simulation of the injection moulding process provides visual and numerical feedback of the part behaviour and eliminates the traditional trial and error approach for optimization. Proper interpretation of the results from simulation can help selecting a suitable material; reduce cycle time and costs on mould modification. Patcharaphun,et al. [6] used a commercial software package (Moldflow) to predict the fiber orientation distribution within the weldline area of push-pull-processing parts. Song, et al. [7] had applied the orthogonal experiment method and numerical simulation software 
(Moldflow), discussed the influence of different process parameters on the molding process for ultra-thin wall plastic parts.

\section{The role and implications of DOE}

Design of Experiment (DOE) was invented by R.A. Fisher in England in early 1920. It was Fisher's idea that it was much better to vary all the factors simultaneously in what he called a "factorial design". The purpose of experimental design is to minimize the number of experiments (runs) required to identify which experiment is significantly related to the desire output variables (responses). This allows for a large number of variables to be studied and analyzed easily and economically. For further information on DOE refer to the work done by of Montgomery [8]. Additionally, there were several papers addressing the importance of DOE. Cupello [9] stated that DOE is one of the few reliable and effective tools for developing globally competitive products and processes. Rowand [10] argued that employees from equipment operators to the plant managers could benefit from the use of DOE. At the same time, various industries have employed the DOE method over the years to improve products and processes, increase productivity and reduce costs. It is a powerful and effective method to solve challenging quality problems $[11,12]$. Many quality techniques and concepts such as statistical process control (SPC) are directed toward improving quality at the downstream processes and operations by emphasizing control charts and inspection. DOE, on the other hand, emphasizes the upstream processes and operations, focusing on developing products and processes that are well-designed.

\section{The role of DOE in the optimization of plastic injection moulding}

The role of DOE in the optimization of plastic injection moulding processes has received attention in the literature. The nature of DOE applications as well as their goals has been quite different. The following represents the literature related to the broad use of DOE in the plastic injection moulding industry. Mapleston [13] in a brief paper indicated that the optimization has produced dramatic improvements in injection moulding processes at a company. Morgan [14] argued that the optimization process for injection moulding industry does not need to stop at the quality control department in order for the full range of benefits to be obtained. Speight [15] discussed the moulding process control system that resulted in a faster turnaround, higher quality, and lower costs for revising a design and modification of a mould. 


\section{Objective of the study}

In this paper the authors used a case study to investigate the injection moulding machine parameters which will affect the dimensions (length and width) of a plastic cell phone shell. The machine process setting currently caused variations in the dimensions exceeding the specification limit. Therefore the experiment is needed to identify the optimal machine parameter setting which could be maintain the dimensions (length and width) closest to the target value with smallest possible variation. Statistical results and analysis are used to provide better interpretation of the experiment.

\section{Methedology}

Factorial design is a collection of mathematical and statistical techniques which used in the modelling and analysing of problems. The objective is to optimise the response [8]. Factorial design also quantifies relationships among one or more measured responses and the input factors [16].

In this study, the approximation of the mathematical model will be proposed using the fitted second-order regression model. The necessary data for building the response model are generally collected by the experimental design. The experimental design adopts the full factorial design with center point. The experimental factorial design is combinations of the factors at two levels (high and low) with two center points. The factorial design is a sequential procedure for determining the optimal injection machine parameters[16,17].

In order to determine if there exist a relationship between the factors and the responses, the data must be analysed in a statistically manner using regression. A regression is performed in order to describe the data collected whereby an observed, response variable is approximated based on a functional relationship between the estimated response $\left(y_{\text {est }}\right)$ and factors $\left(x_{1}, x_{2}, \ldots, x_{1}\right)$.In this case study exist a second order relationship between response and three factors. A second order equation, $y_{\text {est }}=b_{0}+b_{1} x_{1}+$ $b_{2} x_{2}+b_{3} x_{3}+b_{4} x_{1} x_{2}+b_{5} x_{1} x_{3}+b_{6} x_{2} x_{3}+$ error, was used to describe the functional relationship between the estimated response, $y_{\text {est }}$ and the factors $x_{1}, x_{2}$, and $x_{3}$. The least square technique is being used to fit a model equation containing the said factors by minimising the residual error measured by the sum of square deviations between the actual and the estimated responses. This involves the calculation of estimates for the regression coefficients, i.e. the coefficients of the model variables including the intercept or constant term. The calculated coefficients or the model 
equation need to however be tested for statistical significance. In this respect, the following tests are performed by using Design Expert Software Version 7 (Stat-Ease Inc., Minneapolis, USA) [16].

\section{Analysis of variance (ANOVA)}

The method used to compare the magnitude of estimated effects of factors with the magnitude of experimental error is called ANOVA. If the magnitude of a factor effect is large when compared with experimental error, it is decided that the changes in the selected response cannot occur by chance and those changes in the response can be considered to be the effects of the factors. The factors causing a variation in the response are called significant. In this study, $F$-test was used in the ANOVA.

\section{Test for significance of the regression model}

This test is performed as an ANOVA procedure by calculating the $F$-ratio, which is the ratio between the regression mean square and the mean square error. The $F$-ratio, also called the variance ratio, is the ratio of variance due to the effect of a factor (in this case the model) and variance due to the error term. This ratio is used to measure the significance of the model under investigation with respect to the variance of all the terms included in the error term at the desired significance level, $\alpha$. A significant model is desired.

\section{Test for significance on individual model coefficients}

This test forms the basis for model optimisation by adding or deleting coefficients through backward elimination, forward addition or stepwise elimination/addition/exchange. It involves the determination of the $P$-value or probability value, usually relating the risk of falsely rejecting a given hypothesis. For example, a "Prob. $>F$ " value on an $F$-test tells the proportion of time you would expect to get the stated $F$-value if no factor effects are significant. The "Prob. $>F$ " value determined can be compared with the desired probability or $\alpha$-level. In general, the lowest order polynomial would be chosen to adequately describe the system.

\section{Test for lack-of-fit}

The test statistic for lack-of-fit is the ratio between the lack-of-fit mean square and the pure error mean square. As previously, this $F$-test statistic can be used to determine as to whether the lack-of-fit error is significant or otherwise at the desired significance level, $\alpha$. Insignificant lack-of-fit is 
desired as significant lack-of-fit indicates that there might be contributions in the factor-response relationship that are not accounted for by the model. Additionally, checks need to be made in order to determine whether the model actually describes the experimental data. The checks performed here include determining the various coefficient of determination, $R^{2}$. These $R^{2}$ coefficients have values between 0 and 1 . The lack-of-fit must be insignificant. The various coefficient of determination, $R^{2}$ values should be close to 1.

\section{Graphical residuals analysis}

The adequacy of the model is also investigated by the examination of residuals [8]. The residuals, which are the difference between the respective, observe responses and the predicted responses are examined using the normal probability plots of the residuals and the plots of the residuals versus the predicted response. If the model is adequate, the points on the normal probability plots of the residuals should form a straight line. On the other hand the plots of the residuals versus the predicted response should contain no obvious patterns.

\section{Expeimental Set-up}

The material used in this experiment was commercially available polycarbonate (PC) material. The material was pre-conditioned at $120^{\circ} \mathrm{C}$ for four hours using a dehumidifying drier before moulding.In this experiment three factors are being studied and their levels are given in Table 1. The average value of a factor is equal to center point. The three factors are mould temperature, injection pressure and screw rotation speed and it is labeled as $\mathrm{A}, \mathrm{B}$ and $\mathrm{C}$ respectively.

The levels of the factors determined according to our experience about the process and from the literature research. The injection moulding machine process setting in use currently caused variations in the dimensions exceeding the specification limit of length and width of cell phone shell. The specification limit for the length and width are $93.49 \pm 0.2 \mathrm{~mm}$ and $45.93 \pm$ $0.2 \mathrm{~mm}$ respectively. The objective of this experiment is to identify the optimal machine parameter setting which could be set to maintain the dimensions closest to the target values with smallest possible variation. The target values for length and width are $93.49 \mathrm{~mm}$ and $45.93 \mathrm{~mm}$ respectively. 
Table 1: Experimental control factors and levels

\begin{tabular}{|l|c|c|c|}
\hline \multicolumn{1}{|c|}{ Factor } & Units & Low Level (-) & High Level (+) \\
\hline A. Mould Temperature & ${ }^{\circ} \mathrm{C}$ & 85 & 95 \\
\hline B. Injection Pressure & $\mathrm{kg} / \mathrm{cm}^{2}$ & 2250 & 2400 \\
\hline C. Screw Rotation Speed & $\mathrm{mm} / \mathrm{Sec}$ & 110 & 140 \\
\hline
\end{tabular}

A full two level factorial experimental design with center point was carried out to study on how the above three factors will influence the responses. The number of run (combination of machine parameter setting) needed according to full two-level factorial experimental design method $[8,17]$ for three factors was $2^{3}=8$ and the run was repeated twice. At the same time the authors like to add another two centre points to provide sufficient information on possible curvature in the system. Therefore a total 18 experimental runs were required for these study. At each run, the team leader will record the dimensions of the responses. The dimensions were measured by using digital smart scope machine. Experimental design matrix constructed according to standard order rule which was given in Table 2. Experiments were executed randomly to provide protection against the extraneous factors, which could effect the measured responses. In all experimental runs, the reaction time was considered as $5 \mathrm{~min}$. The resulting responses values are shown in Tables 2 as well. The actual experiment was conducted in the factory with some help from the staff, taking one working day to be completed.

\section{Results and Discussion}

The experimental results as per the experimental plan are shown in Table 2. These results were input into the Design Expert software version 7 for further analysis [16]. Without performing any transformation on the responses, the half normal plot Figure 1-2 revealed for both responses (length and width). The half normal plots shows the effects of factors and the factors lie along the line are negligible. Figure 1 show that, five factors seem to be significant for length those are A, B, C (main factors) AB and AC (two factor interactions). Figure 2 show, four factors seem to be significant for width those are A, B C (main factor) and AC (two factor interactions). The main effect $B$ is the most significant factor associated with length and width. 
Table 2: Experimental design matrix and results

\begin{tabular}{|c|c|c|c|c|c|c|}
\hline Random & Standard & \multicolumn{3}{|c|}{ Factors } & \multicolumn{2}{c|}{ Responses } \\
\hline order & order & A & B & C & Length (mm) & Width (mm) \\
\hline 1 & 16 & 95 & 2400 & 140 & 93.470 & 45.822 \\
\hline 2 & 12 & 95 & 2250 & 140 & 93.440 & 45.813 \\
\hline 3 & 8 & 95 & 2400 & 110 & 93.455 & 45.823 \\
\hline 4 & 11 & 95 & 2250 & 140 & 93.443 & 45.813 \\
\hline 5 & 10 & 85 & 2250 & 140 & 93.429 & 45.800 \\
\hline 6 & 14 & 85 & 2400 & 140 & 93.443 & 45.810 \\
\hline 7 & 3 & 95 & 2250 & 110 & 93.428 & 45.815 \\
\hline 8 & 7 & 95 & 2400 & 110 & 93.456 & 45.822 \\
\hline 9 & 17 & 90 & 2325 & 125 & 93.487 & 45.844 \\
\hline 10 & 5 & 85 & 2400 & 110 & 93.442 & 45.821 \\
\hline 11 & 4 & 95 & 2250 & 110 & 93.427 & 45.812 \\
\hline 12 & 6 & 85 & 2400 & 110 & 93.441 & 45.820 \\
\hline 13 & 15 & 95 & 2400 & 140 & 93.468 & 45.820 \\
\hline 14 & 2 & 85 & 2250 & 110 & 93.426 & 45.810 \\
\hline 15 & 18 & 90 & 2325 & 125 & 93.486 & 45.844 \\
\hline 16 & 1 & 85 & 2250 & 110 & 93.428 & 45.810 \\
\hline 17 & 13 & 85 & 2400 & 140 & 93.441 & 45.808 \\
\hline 18 & 9 & 85 & 2250 & 140 & 93.428 & 45.800 \\
\hline
\end{tabular}

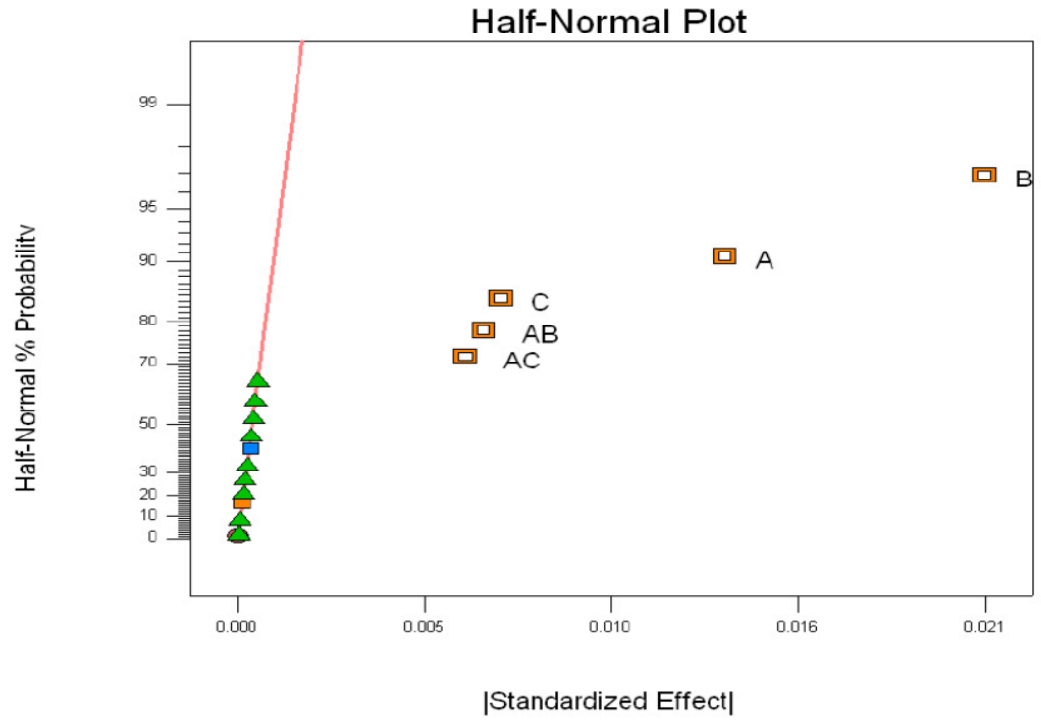

Figure 1: Half normal plot for length 


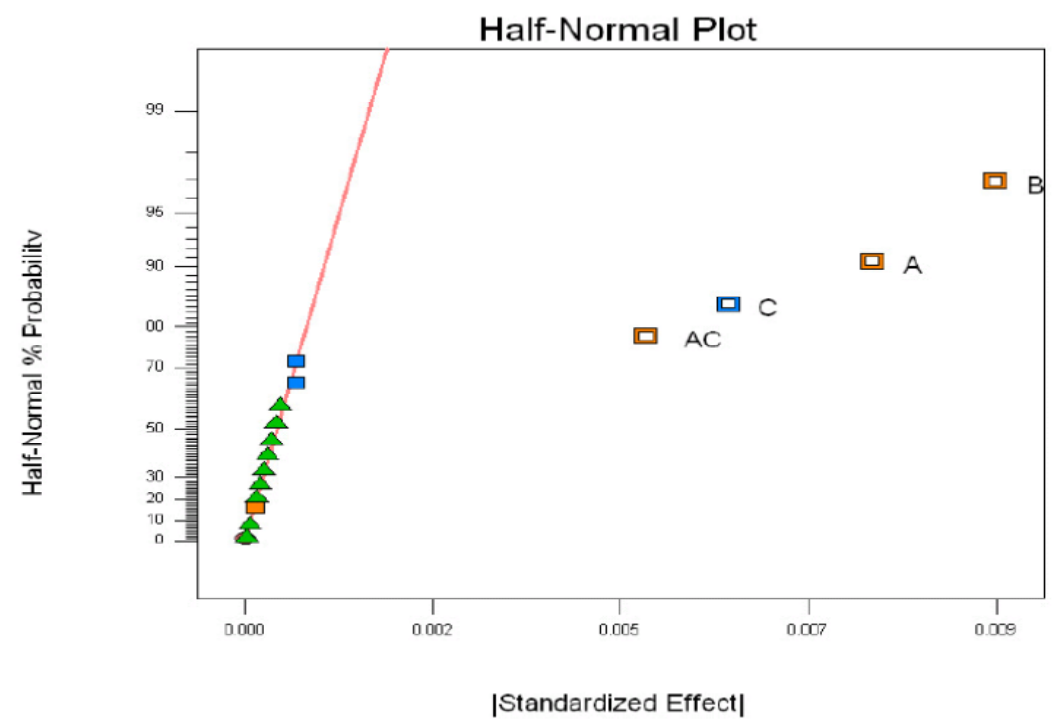

Figure 2: Half normal plot for width

\section{ANOVA analysis}

Table 3 shows the ANOVA table for response length (after backward elimination). The value of "Prob. $>F$ " in table for model is less than 0.05 which indicates that the model is significant, which is desirable as it indicates that the terms in the model have a significant effect on the response. Table 3 show the resulting ANOVA table for the improved model for response length. By selecting the backward elimination procedure in Design Expert software it will automatically reduce the terms that are not significant. These insignificant model term (BC) can be removed and result in an improved model. Results from Table 3 indicate that the model is still significant. However, the main effect of mould temperature (A), injection pressure (B) and speed (C) and the two-level interaction of mould temperature and injection pressure $(\mathrm{AB})$ and mould temperature and speed (AC) are the significant model terms. The lack-of-fit can still be said to be insignificant. 
Table 3: The ANOVA table for the length (after backward elimination)

\begin{tabular}{|c|l|c|l|l|l|l|}
\hline Source & $\begin{array}{l}\text { Sum of } \\
\text { Squares }\end{array}$ & df & $\begin{array}{l}\text { Mean } \\
\text { Square }\end{array}$ & F & Prob $>$ F & \\
\hline Model & $3.06 \mathrm{E}-03$ & 5 & $6.11 \mathrm{E}-04$ & 493.25 & $<0.0001$ & Sig. \\
\hline A & $7.43 \mathrm{E}-04$ & 1 & $7.43 \mathrm{E}-04$ & 599.5 & $<0.0001$ & \\
\hline B & $1.74 \mathrm{E}-03$ & 1 & $1.74 \mathrm{E}-03$ & 1407.24 & $<0.0001$ & \\
\hline C & $2.18 \mathrm{E}-04$ & 1 & $2.18 \mathrm{E}-04$ & 175.65 & $<0.0001$ & \\
\hline AB & $1.89 \mathrm{E}-04$ & 1 & $1.89 \mathrm{E}-04$ & 152.64 & $<0.0001$ & \\
\hline AC & $1.63 \mathrm{E}-04$ & 1 & $1.63 \mathrm{E}-04$ & 131.24 & $<0.0001$ & \\
\hline Curvature & $3.59 \mathrm{E}-03$ & 1 & $3.59 \mathrm{E}-03$ & 2898.35 & $<0.0001$ & Sig. \\
\hline Residual & $1.36 \mathrm{E}-05$ & 11 & $1.24 \mathrm{E}-06$ & & & \\
\hline Lack of Fit & $6.25 \mathrm{E}-07$ & 2 & $3.13 \mathrm{E}-07$ & 0.22 & 0.8095 & not sig. \\
\hline Pure Error & $1.30 \mathrm{E}-05$ & 9 & $1.44 \mathrm{E}-06$ & & & \\
\hline Cor Total & $6.66 \mathrm{E}-03$ & 17 & & & & \\
\hline Std. Dev. & $1.11 \mathrm{E}-03$ & & R-Sq & 0.9956 & & \\
\hline Mean & 93.45 & & Adj R-Sq & 0.9935 & & \\
\hline C.V. \% & $1.19 \mathrm{E}-03$ & & Pred R-Sq & 0.9884 & & \\
\hline PRESS & $3.56 \mathrm{E}-05$ & & Adeq Prec. & 85.37 & & \\
\hline
\end{tabular}

The same procedure is applied on response width and the resulting ANOVA table for the improved model is shown in Table 4. For width, the main effects of mould temperature (A) injection pressure (B) and screw rotation speed (C) and the two-level interaction of mould temperature and screw rotation speed (AC) are the significant model terms. The lack-of-fit also said to be insignificant. Both model from ANOVA Table 3 and 4 shows that the $R^{2}$ value is high, close to 1 , which is desirable. The predicted $R^{2}$ is in reasonable agreement with the adjusted $R^{2}$. The adjusted $R^{2}$ value is particularly useful when comparing models with different number of terms. Adequate precision compares the range of the predicted values at the design points to the average prediction error. Ratios greater than 4 indicate adequate model discrimination. In this particular case the value is well above 4.The following equations are the final models equation in terms of actual factors for both responses:

Length $=95.361-0.025(\mathrm{~A})-6.86 \mathrm{E}-4(\mathrm{~B})-3.579 \mathrm{E}-3(\mathrm{C})+9.167 \mathrm{E}-6(\mathrm{~A} \mathrm{~B})+$ 4.250E-5(AC)

Width $=45.994-3.300 \mathrm{E}-(\mathrm{A})+6.083 \mathrm{E}-5(\mathrm{~B})-3.121 \mathrm{E}-3(\mathrm{C})+3.250 \mathrm{E}-(\mathrm{AC})$ 
Table 4: The ANOVA table for the width (after backward elimination)

\begin{tabular}{|l|l|c|l|l|l|l|}
\hline Source & Sum of Sq. & df & Mean Square & F & Prob $>$ F & \\
\hline Model & $7.99 \mathrm{E}-04$ & 4 & $2.00 \mathrm{E}-04$ & 188.87 & $<0.0001$ & Sig. \\
\hline A & $2.33 \mathrm{E}-04$ & 1 & $2.33 \mathrm{E}-04$ & 219.96 & $<0.0001$ & \\
\hline B & $3.33 \mathrm{E}-04$ & 1 & $3.33 \mathrm{E}-04$ & 315.01 & $<0.0001$ & \\
\hline C & $1.38 \mathrm{E}-04$ & 1 & $1.38 \mathrm{E}-04$ & 130.58 & $<0.0001$ & \\
\hline AC & $9.51 \mathrm{E}-05$ & 1 & $9.51 \mathrm{E}-05$ & 89.91 & $<0.0001$ & \\
\hline Curvature & $1.63 \mathrm{E}-03$ & 1 & $1.63 \mathrm{E}-03$ & 1544.99 & $<0.0001$ & Sig. \\
\hline Residual & $1.27 \mathrm{E}-05$ & 12 & $1.06 \mathrm{E}-06$ & & & \\
\hline Lack of Fit & $3.19 \mathrm{E}-06$ & 3 & $1.06 \mathrm{E}-06$ & 1.01 & 0.4337 & not sig. \\
\hline Pure Error & $9.50 \mathrm{E}-06$ & 9 & $1.06 \mathrm{E}-06$ & & & \\
\hline Cor Total & $2.45 \mathrm{E}-03$ & 17 & & & & \\
\hline & & & & & & \\
\hline Std. Dev. & $1.03 \mathrm{E}-03$ & & R-Sq. & 0.9844 & & \\
\hline Mean & 45.82 & & Adj R-Sq & 0.9792 & & \\
\hline C.V. $\%$ & $2.24 \mathrm{E}-03$ & & Pred R-Sq & 0.9669 & & \\
\hline
\end{tabular}

\section{Graphical residuals analysis}

The normal probability plots of the residuals and the plots of the residuals versus the predicted response for length and width are shown in Figures 3-6. A check on the plots in Figures 3 and 5 revealed that the residuals generally fall on a straight line implying that the errors are distributed normally. Also Figures 4 and 6 revealed that they have no obvious pattern and unusual structure. This implies that the models proposed are adequate and there is no reason to suspect any violation of the independence or constant variance assumption.

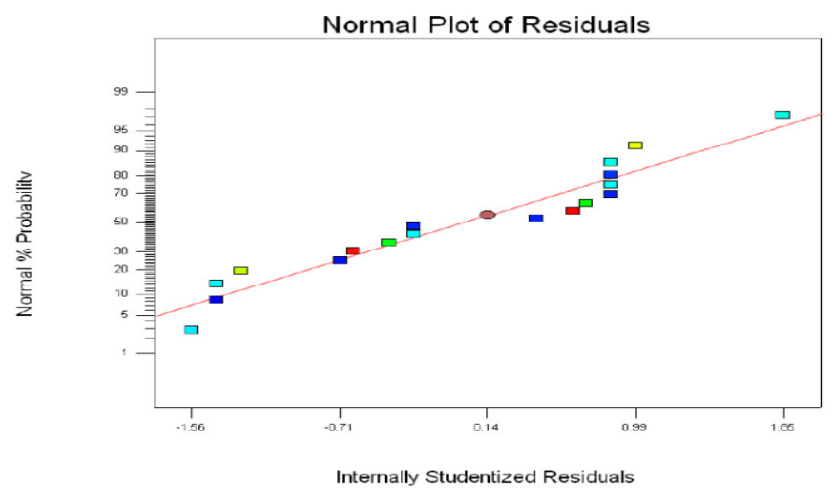

Figure 3: Normal probability plot of residuals for length. 


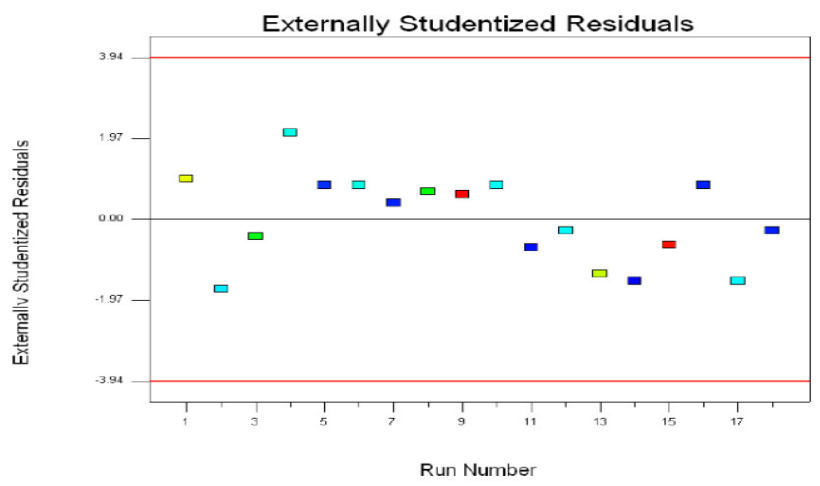

Figure 4: Plot of residuals vs. predicted for length.

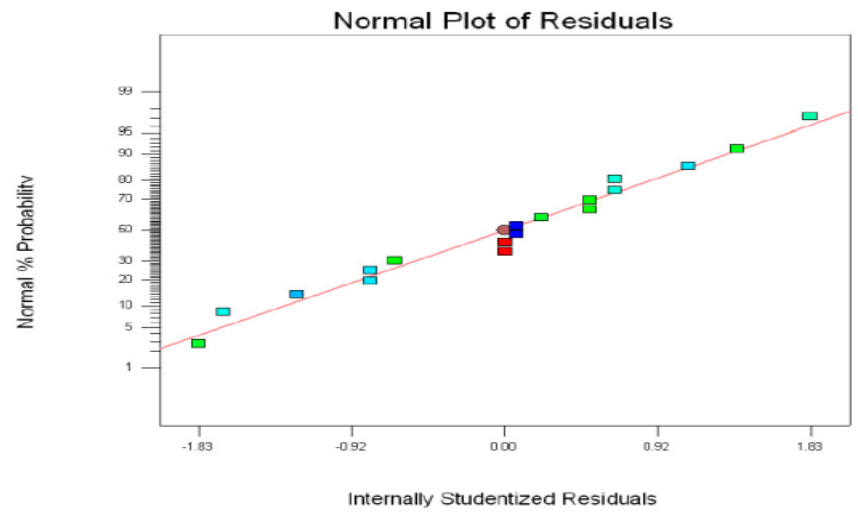

Figure 5: Normal probability plot of residuals for width.

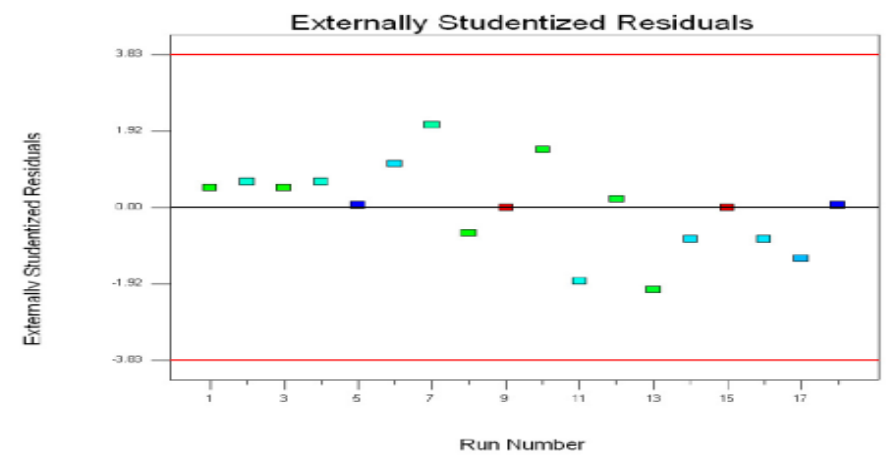

Figure 6: Plot of residuals vs. predicted for width 


\section{Examine main effect and interactions}

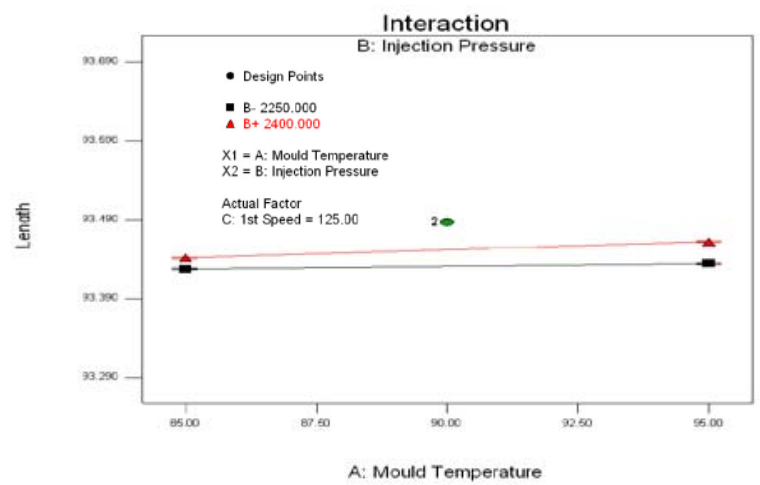

Figure 7: Interaction graph of A versus B (length)

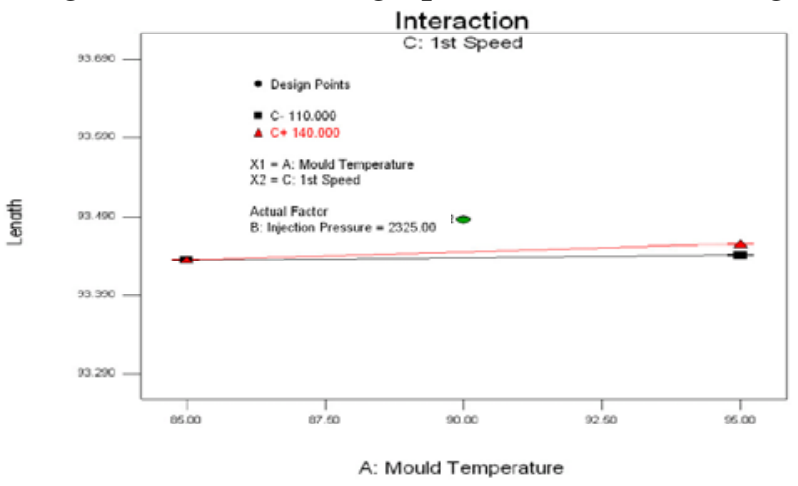

Figure 8: Interaction graph of A versus C (length).

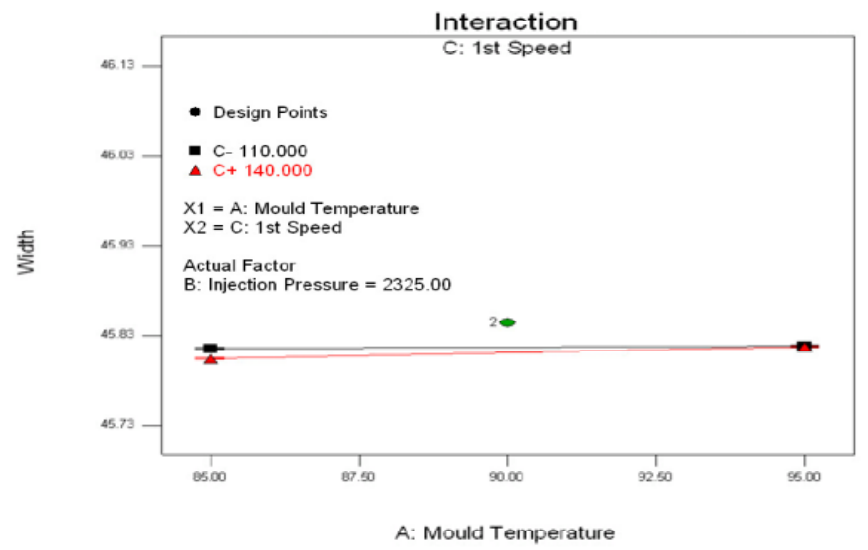

Figure 9: Interaction graph of A versus C (width). 


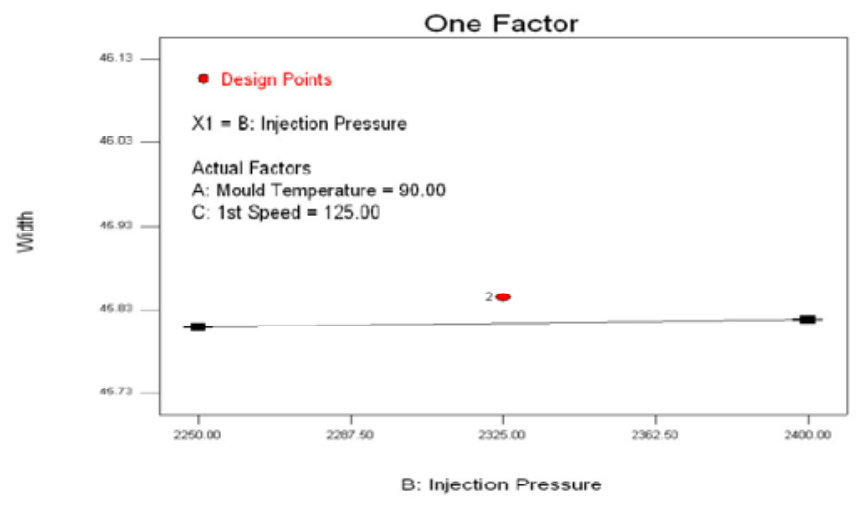

Figure 10: Main effect B for width

In the interaction graph those points that have non overlapping intervals are significantly different and the points overlapping intervals not significantly different. Figure 7 show the interaction graph of AB for length. The spread of the points on the right side of the graph (where mould temperature is high) is higher than the spread between the points at the left side of the graph (where mould temperature is low.) In other words, the effect of length is more significant at the high level of mould temperature $\left(\mathrm{A}^{+}\right)$and high injection pressure $(\mathrm{B}+)$ to increase the length current dimension to target value $(93.49 \mathrm{~mm})$. Figure 8 show the interaction graph of AC for length. The points on the right side of the graph (where mould temperature is high) is significantly different and the points at the left side of the graph (where mould temperature is low) are not significantly different. In other words, the effect of length is more significant at the high level of mould temperature $(\mathrm{A}+)$ and high level of speed $(\mathrm{C}+)$ to increase the current length dimension to target value $(93.49 \mathrm{~mm})$. Figure 9 show the interaction graph of AC for width. The points on the left side of the graph (where mould temperature is low) is significantly different and the points at the right side of the graph (where mould temperature is high) are not significantly different. In other words, the effect of width is more significant at the low level of mould temperature (A-) and low level of speed (C-) to increase the current width dimension to target value $(45.93 \mathrm{~mm})$. Figure 10 show that the effect of main factor effect injection pressure (B) with width. It is very clear that factor B do not have any significant effect on the response width. Therefore economically it is very clear that the width can be maintained close to target value $(45.93 \mathrm{~mm})$ by reducing the injection pressure (B-). 
Figures 7 - 10 show that the effect (main and interaction factor effect) does not have any significant effect on the responses length and width because both line (red and black) almost super impose each other and the gradient of the lines do not have any significant different. In other word, Figure $7-9$ show that the gradient of the red and black lines are almost same and the lines are almost horizontal. Therefore economically it is very clear that the response dimensions can be maintained close to target values (93.49 $\mathrm{mm}$ and $45.93 \mathrm{~mm}$ ) by setting the three injection machine parameters mould temperature, injection pressure and screw rotation speed at lower level (A-, B- and C-).If look carefully the Figure 7 -10 it is clear that the most nearest points (Design Points) to the target values of the length and width are obtainable when the factors $\mathrm{A}, \mathrm{B}$ and $\mathrm{C}$ are at middle of the experimented range, that is when $\mathrm{A}$ is $90{ }^{\circ} \mathrm{C}$, B is 2325 $\mathrm{km} / \mathrm{cm}^{2}$ and $\mathrm{C}$ is $125 \mathrm{~mm} / \mathrm{sec}$. The same observation can also be made from the 3D surface graphs for length and width which are shown in Figure $11-12$. Therefore practically the authors decide that the center parameter setting $\left(90{ }^{\circ} \mathrm{C}, 2325 \mathrm{~km} / \mathrm{cm}^{2}\right.$ and $\left.125 \mathrm{~mm} / \mathrm{sec}\right)$ is the optimised parameter to achieve the target dimensions for responses length and width.

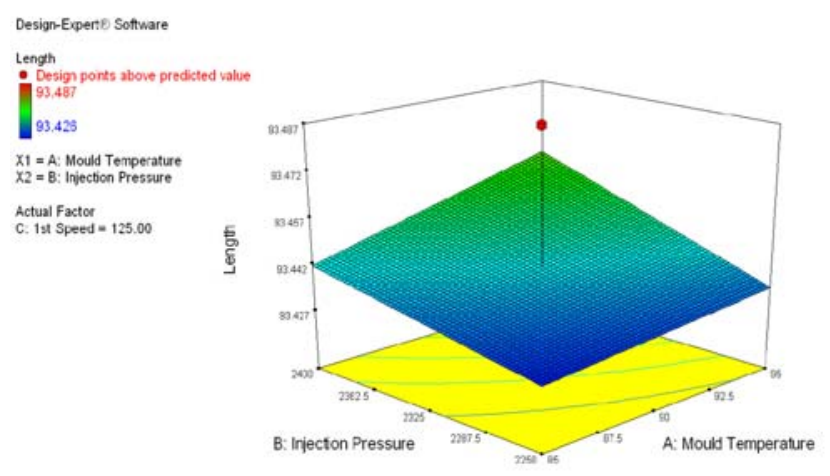

Figure 11: 3D view $\mathrm{AB}$ interaction for length 


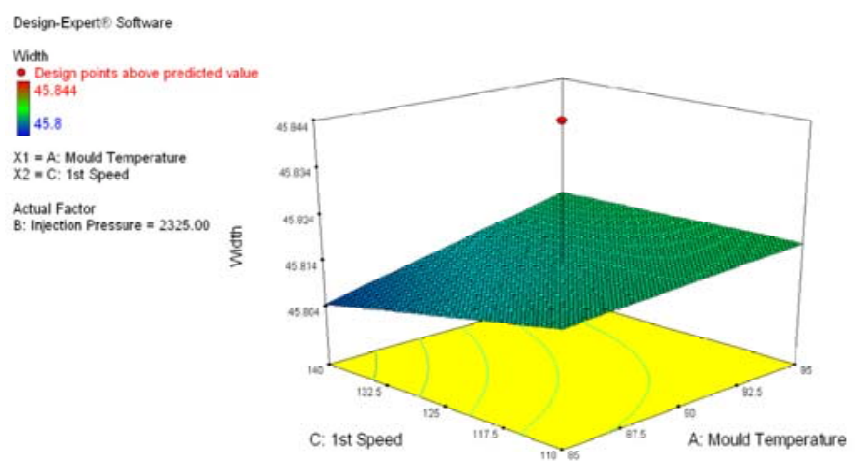

Figure 12: 3D view AC interaction for width.

\section{Confirmation Run}

Before switch to entire manufacturing operation to the above setting and produce high volume of parts, need to some verification runs. For this experiment the authors decided to produce 25 samples. A different lot Polycarbonate (PC) material was used in this verification run. The purpose of this verification run was to validate that the center parameter setting ( $A$ is $90{ }^{\circ} \mathrm{C}$, B is $2325 \mathrm{~km} / \mathrm{cm}^{2}$ and $\mathrm{C}$ is $125 \mathrm{~mm} / \mathrm{sec}$ ) is the optimised parameter to achieve the target dimension. The result show (Figure $13-14$ ) that the 25 samples the length and width are near to target values.

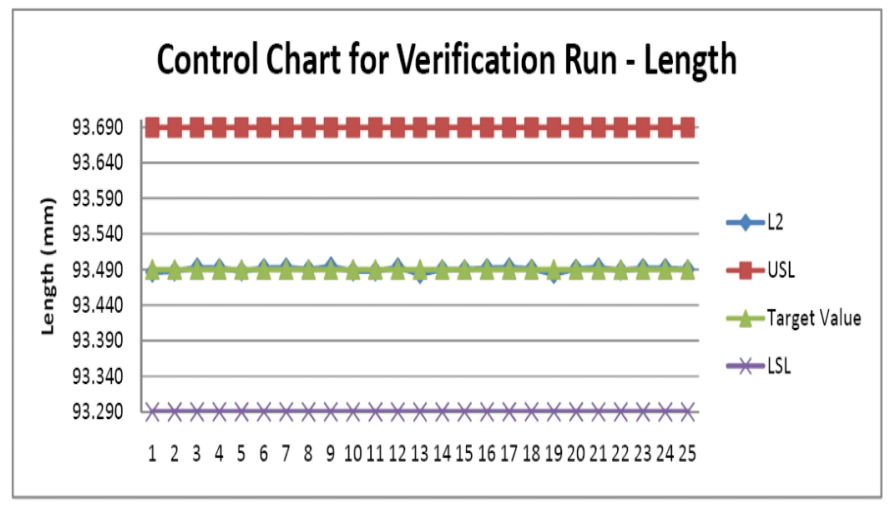

Figure 13: Verification Run for response - Length 


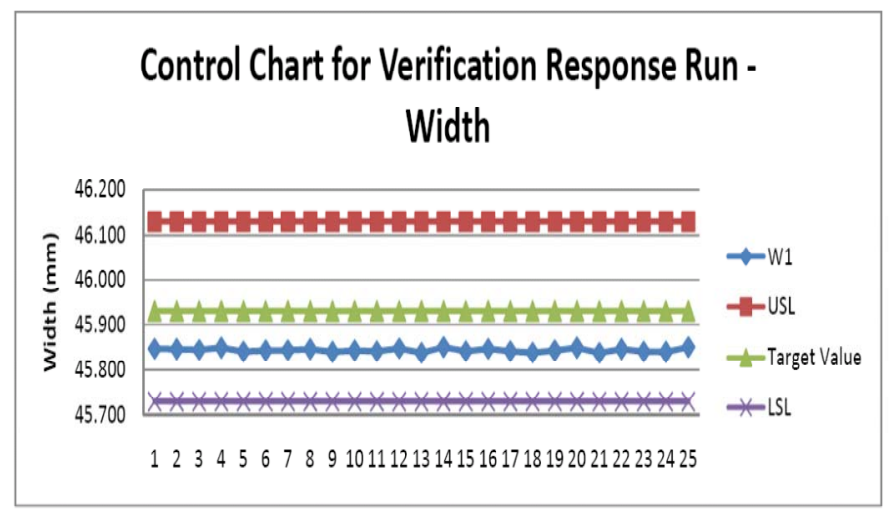

Figure 14: Verification Run for response - Width

\section{Conclusion}

In this paper a DOE approach (2-level factorial design with center point) for optimising the injection moulding process was investigated. The injection moulding machine parameters which will affect the dimensions (length and width) in a plastic cell phone shell studied. The significant factors affecting the length and width of the cell phone shell were identified from ANOVA. The optimal process parameters to maintain the dimensions closest to the target value were identified (mould temperature is $90{ }^{\circ} \mathrm{C}$, injection pressure $2325 \mathrm{~km} / \mathrm{cm}^{2}$ and screw rotation speed is 125 $\mathrm{mm} / \mathrm{sec}$ ) from interaction graphs and 3D views. Statistical results and analysis are used to provide better interpretation of the experiment. The models are form from ANOVA and the models passed the tests for normality and independence assumptions. Confirmation run with the above center parameter setting determined that target dimensions for responses length and width were achievable. It is noted here that the results obtained in this study were quite satisfactory for the concerned industry since they were able to achieve the target values for the length and width of cell phone shell.

\section{Acknowledgement}

The main author gratefully acknowledges the financial support of Curtin University of Technology, Sarawak Campus, Research and Development Department. He also would like to thank Prof. Awang Bono and A/Prof. Jumat Sulaiman from University Malaysia Sabah, Mr. Prem Kumar and 
Mr. Loh Kim Long for their contribution and technical support of the work.

\section{References}

1. Thin T (1996) Asian plastics news, July/August, Wiley, New York, pp 12-14

2. Crawford RJ (1989) Plastic engineering, 2nd edn. Pergamon, Oxford

3. Leo V, Cuvelliez Ch (1996) The effect of the packing parameters, gate geometry, and mold elasticity on the final dimensions of a molded part. Polym Eng Sci 36:1968-1977

4. Huang MC, Tai CC (2001) The effective factors in the warpage problem of an injection-molded part with a thin shell feature. $\mathrm{J}$ Mater Process Technol 110:1-9

5. Ozcelik B, Erzumlu T (2005) Determination of effecting dimensional parameters on warpage of thin shell plastic parts using integrated response surface method and genetic algorithm. Int Commun Heat Mass Transf 32:1085-1094

6. Patcharaphun, S., Zhang, B., \& Mennig, G. (2007). Simulation of three-dimensional fiber orientation in weldline areas during pushpull-processing. Journal of Reinforced Plastics and Composites, 26(10), 977-985.

7. Song, M. C., Liu, Z., Wang, M. J., Yu, T. M., \& Zhao, D. Y. (2007). Research on effects of injection process parameters on the molding process for ultra-thin wall plastic parts. Journal of Materials Processing Technology, 178(1-3), 148-153.

8. D.C. Montgomery, Design and Analysis of Experiments, 6th ed., Wiley, New York, 2005.

9. Cupello, J.M. (1999), "Training technologies in experimental design”, Research Technology Management, Vol. 42 No. 5, pp. 47-50.

10. Rowand, R. (1988), “A matter of survival”, Automotive News, September 5, p. E38.

11. Sofuoglu, H. (2006). A technical note on the role of process parameters in predicting flow behavior of plasticine using design of experiment. Journal of Materials Processing Technology, 178(1-3), 148-153.

12. Yang, Y. K. (2006b). Optimization of injection-molding process of short glass fiber and polytetrafluoroethylene reinforced 
polycarbonate composites via design of experiments method: A case study. Materials and Manufacturing Processes, 21(8), 915921.

13. Mapleston, P. (1999), "Real-time process control is said to provide perfect shots”, Modern Plastics, Vol. 29 No. 8, pp. 29-30.

14. Morgan, C. (1999), "Auxiliary equipment: a management issue”, Molding Systems, Vol. 57 No. 2, pp. 34-8.

15. Speight, R.G. (1998), "Molding process optimization comes of age”, Molding Systems, Vol. 56 No. 8, pp. 20-3.

16. Design-Expert Software, Version 7, User's Guide, Technical Manual, Stat-Ease Inc., Minneapolis, MN, 2000.

17. Myers RH, Montgomery DC (1995) Response surface methodology: process and product optimization using designed experiments. Wiley, New York

18. D.D. Steppan, J. Werner, R.P. Yeater, Essential regression and experimental design for chemists and engineers, 1998. http://geocities.com/ iliconValley/Network/1032/CGPage1.html. 
